\title{
ASSOCIAÇÃO DE FUNGOS MICORRÍZICOS ARBUSCULARES E CULTIVARES MICROPROPAGADAS DE ANTÚRIO $\left({ }^{1}\right)$
}

\author{
GIULIO CESARE STANCATO $\left(2^{*}\right)$; ADRIANA PARADA DIAS DA SILVEIRA $\left({ }^{3}\right)$
}

\begin{abstract}
RESUMO
Para a formação de mudas, plântulas micropropagadas de antúrio (Anthurium andraeanum) são submetidas a uma das etapas mais críticas na cultura de tecidos de plantas que é a da aclimatização. Uma forma de se estimular a autotrofia pode ser o estabelecimento da associação de fungos micorrízicos e as raízes das plântulas de antúrio. Assim, com o objetivo de avaliar o efeito da associação micorrízica em plântulas de antúrio, foi realizado um experimento, em casa de vegetação, empregando-se as cultivares IAC Astral, IAC Eidibel, IAC Juréia, IAC Luau, IAC Netuno e IAC Ốmega e os fungos micorrízicos arbusculares Glomus intraradices, Glomus etunicatum e Acaulospora sp., em substrato orgânico, na fase de aclimatização das plântulas micropropagadas. Os resultados permitiram concluir que houve resposta das cultivares de antúrio à micorrização, em termos de produção de matéria seca, e que a eficiência simbiótica variou com a cultivar e o fungo micorrízico associado.
\end{abstract}

Palavras-chave: Anthurium andraeanum, aclimatização, micorriza arbuscular, muda micropropagada, plantas ornamentais tropicais.

\section{ABSTRACT \\ MYCORRHIZAL FUNGI AND MICROPROPAGATED CULTIVARS OF ANTHURIUM ASSOCIATIONS}

One of the most important steps on micropropagated Anthurium plantlets is the acclimatization. Mycorrhization could be a process that helps the plantlets to change to the autotrophic state. The objective was to evaluate the effect of the mycorrhizal association on the growth of Anthurium cultivars. A experiment was conducted under greenhouse conditions, using the cultivars IAC Astral, IAC Eidibel, IAC Juréia, IAC Luau, IAC Netuno and IAC Ômega and the arbuscular mycorrhizal fungi Glomus intraradices, Glomus etunicatum and Acaulospora sp., in organic substrate, at the plantlets acclimatization stage. The results showed that there was increase in shoot dry matter in mycorrhizal plantlets and that the symbiotic efficiency varied according to the cultivar and arbuscular mycorrhizal fungus.

Key words: Anthurium andraeanum, acclimatization, arbuscular mycorrhiza, micropropagated plantlets, ornamental tropical plants.

$\left.{ }^{1}\right)$ Recebido para publicação em 3 de agosto de 2004 e aceito em $1 .^{\circ}$ de junho de 2006.

$\left({ }^{2}\right)$ Centro de Horticultura, Instituto Agronômico (IAC), Caixa Postal 28, 13001-970 Campinas (SP). E-mail: stancato@iac.sp.gov.br. *Autor correspondente.

$\left({ }^{3}\right)$ Centro de Solos e Recursos Ambientais, Instituto Agronômico (IAC), Caixa Postal 28, 13001-970 Campinas (SP). E-mail: apdsil@iac.sp.gov.br 


\section{Introdução}

$\mathrm{Na}$ atualidade, em muitos países, o antúrio, Anthurium andraeanum, tem se destacado como planta ornamental e pode ser cultivado comercialmente como planta de vaso, flor de corte ou como planta de jardim. De acordo com Matthes e CASTRo (1989), o gênero Anthurium (Araceae) compreende mais de seiscentas espécies, normalmente herbáceas, perenes, epífitas, sendo nativo da América do Sul, e a maioria é de espécies ornamentais. Durante o ano todo produz hastes florais que emergem da base de cada folha, e a seqüência nova folha:nova haste floral é mantida durante toda a vida da planta.

Devido à ocorrência de protoginia no antúrio, que induz à polinização cruzada, a propagação em grande escala por sementes não é viável, e os produtores têm buscado cultivares cujos propágulos são obtidos por métodos de micropropagação ou clonagem in vitro, que favorecem a uniformidade das plantas e das hastes florais. É necessário porém, que as plântulas micropropagadas sejam submetidas a uma das etapas mais críticas na cultura de tecidos de plantas que é a da aclimatização e formação das mudas. Essa etapa envolve a transição de uma condição heterotrófica in vitro para uma condição autotrófica, na qual as plântulas realizam fotossíntese e estão suscetíveis ao déficit hídrico (GRATTAPAGLia e MACHADO, 1990). Em geral, o controle do ambiente é indicado como uma das estratégias empregadas na aclimatização e formação das mudas (Tombolato et al., 2004), sendo de grande importância na promoção do crescimento, desenvolvimento e morfologia de plântulas in vitro (KozAI et al., 1987; KozAI, 1991). Uma forma de se estimular a autotrofia pode ser o estabelecimento da associação de fungos micorrízicos em raízes de plântulas micropropagadas. Tais associações, denominadas de micorrizas, ocorrem na maioria das espécies vegetais, e a presença desses fungos no sistema radicular das plantas pode aumentar a absorção de nutrientes do solo, principalmente de elementos minerais imóveis como o fósforo. Esse aumento da capacidade de absorção é devido ao crescimento do fungo além das raízes, ramificando-se no solo e, em decorrência, podendo proporcionar um ganho no crescimento da planta e até um acréscimo na produção, principalmente em solos de baixa fertilidade. Além disso, existem evidências de que as micorrizas podem aumentar a tolerância das plantas ao déficit hídrico e aos patógenos que atacam o sistema radicular (SILveIRA, 1992). Os efeitos benéficos da micorrização em plantas ornamentais já foram observados em Chrysanthemum moriflorium (Silveira e Lima, 1996; SOHN et.,2003), Euphorbia pulcherrima (KAYE et al., 1984), Dendranthema grandiflora (JoHnson et al, 1982), Gerbera jamensoni (Silva et al., 1991), Pelargonium hortorum (Sweatt e DAvis Jr, 1984), Petunia hybrida, Tagetes erecta, Callistephus chinensis, Papaver rhoeas e Dianthus caryophyllus (GAUR E AdHoleya, 2005), Rosa (KLINGEMAN et al., 2005), Tagetes spp (Linderman e DAvis, 2004) e outros. Os efeitos positivos da micorrização de plantas ornamentais, relacionados tanto à produção de mudas, de flores de corte quanto de plantas comercializadas em vasos, são de grande interesse, principalmente pela redução do tempo na obtenção de mudas, aumento no índice de pegamento no transplantio e aumento na uniformidade das plântulas. Portanto, a micorrização de plântulas micropropagadas pode ser um processo altamente benéfico para obtenção de plantas sadias e uniformes, como, por exemplo, constatado para hortênsia (VARMA e SCHUEPr, 1994).

Tendo em vista esses fatos, o presente trabalho teve como objetivo avaliar o efeito da associação micorrízica em plântulas de antúrio, já que seu cultivo está se expandindo no Estado de São Paulo e são escassas as informações disponíveis sobre essa planta e a influência de fatores bióticos e abióticos sobre seu crescimento e desenvolvimento. Foram empregadas cultivares de Anthurium andraeanum Lindl., espécie vegetal utilizada na produção de flores de corte devido ao grande tamanho e colorido das suas hastes florais.

\section{Material e Métodos}

As plântulas obtidas por micropropagação, segundo Matthes e CAstro (1989), foram transplantadas individualmente para vasos de polipropileno de $300 \mathrm{~mL}$, contendo substrato à base de casca de Pinus sp, turfa e vermiculita com a seguinte análise química: $\mathrm{pH}-4,4$; $\mathrm{EC}-2,4 \mathrm{dS} \mathrm{m}^{-1}$; $\mathrm{N}-\mathrm{NH}_{4}-3,4 ; \mathrm{N}^{-\mathrm{NO}_{3}}-90 ; \mathrm{P}-1,8 ; \mathrm{K}-110 ; \mathrm{Ca}-166 ; \mathrm{Mg}-$ 103; B- 0,4; Cu- 0,1; Fe - 0,2; Mn- 2,0 e Zn- 0,2 mg L-1. No primeiro mês, as plântulas permaneceram em estufa "pad \& fan", sob $50 \%$ de luminosidade, umidade relativa na faixa de $95 \pm 3 \%$ e a temperatura variando de $25-30{ }^{\circ} \mathrm{C}$. Após esse período, as plântulas foram transferidas para casa de vegetação sob $70 \%$ de sombra e temperatura variando de 15 a $30^{\circ} \mathrm{C}$, por um período de onze meses, de acordo com Tombolato et al. (2004). O sistema de regas foi realizado para manter a umidade do substrato entre 100 e $50 \%$ da sua capacidade de campo. Foram empregadas seis cultivares de Anthurium andraeanum Lindl. - IAC Astral, IAC Eidibel, IAC Juréia, IAC Luau, IAC Netuno e IAC Ômega, desenvolvidas pelo Instituto Agronômico (Tombolato et al., 2005). Por ocasião do transplantio das plântulas, foi realizada a inoculação 
dos fungos micorrízicos arbusculares (FMA) Acaulospora sp. Bhutan, Glomus intraradices Schenck \& Smith e Glomus etunicatum Becker et Gerdemann, previamente multiplicados em braquiária, cujos inóculos constaram de cerca de 400 esporos, pedaços de raiz colonizada e micélio adicionados ao substrato.

Por ocasião da finalização do experimento, as plântulas foram separadas em parte aérea e raiz, para a determinação da massa da matéria seca e da colonização micorrízica. A matéria seca da parte aérea foi obtida após secagem em estufa com circulação forçada de ar, a $60-70{ }^{\circ} \mathrm{C}$, até peso constante. Para avaliar a colonização micorrízica, as raízes foram coradas com trypan blue (Phillips e HAYMAn, 1970) e a estimativa foi realizada pelo método da lâmina, com dez segmentos de raiz, examinados em microscópio com aumento de 10x40 (Giovannetti e Mosse, 1981).

A eficiência da simbiose (ES), em termos de crescimento da parte aérea, foi calculada da seguinte forma: ES $(\%)=[$ (matéria seca de plantas micorrizadas - matéria seca de plantas não micorrizadas) / matéria seca de plantas micorrizadas] x 100.

O delineamento experimental foi inteiramente ao acaso, em esquema fatorial $6 \times 4$, com cinco repetições, sendo empregado o teste F para análise de variância e o teste de Tukey a $5 \%$ para comparação das médias dos tratamentos.

\section{Resultados e Discussão}

Nos dados apresentados na tabela 1, verificase o acúmulo de matéria seca ocorrido após um período de doze meses, entre a aclimatização e a formação das mudas de antúrio.
Em relação à cultivar IAC Astral, o acúmulo de matéria seca nas mudas não micorrizadas foi significativamente menor do que nas plantas micorrizadas e o ganho de biomassa foi de $50 \%$ em média, não havendo diferença entre as espécies de FMAs empregadas. A eficiência simbiótica dos fungos (ES) foi de 34\% (Tabela 2), mostrando que a resposta à inoculação foi pouco influenciada pela espécie de fungo, pois todos os FMAs tiveram o mesmo grau de eficiência na promoção do crescimento das plântulas dessa cultivar.

Para a cultivar IAC Eidibel, plântulas colonizadas por G. intraradices ou Acaulospora sp. tiveram maior acúmulo de matéria seca, em torno de $50 \%$ (Tabela 1), quando comparadas com as mudas não micorrizadas, enquanto as colonizadas por G. etunicatum não diferiram da testemunha, embora tenha ocorrido um acréscimo de $29 \%$ na matéria seca da parte aérea. A eficiência das simbioses estabelecidas por $G$. intraradices ou Acaulospora sp. foi de 33\% (Tabela 2). Também na cultivar Juréia, os fungos que promoveram maior produção de matéria seca foram $G$. intraradices e Acaulospora sp., causando incrementos de $44 \%$ e $49 \%$ respectivamente (Tabela 1 ), sendo que a eficiência das simbioses estabelecidas foi em torno de $30 \%$ (Tabela 2). As plantas colonizadas por $G$. etunicatum não diferiram da testemunha, mas promoveram um incremento de $34 \%$ na parte aérea. Esses mesmos resultados foram observados para a cultivar Luau, e os incrementos na produção de matéria seca foram de $71 \%$ e $92 \%$ para $G$. intraradices e Acaulospora sp., respectivamente (Tabela 1). Quanto ao G. etunicatum, o incremento foi de $30 \%$, mas não diferiu da testemunha. A eficiência das simbioses estabelecidas pelo $G$. intraradices e Acaulospora sp foi de $42 \%$ e $48 \%$ respectivamente (Tabela 2 ).

Tabela 1. Acúmulo de matéria seca de plântulas de cultivares de Anthurium andraeanum colonizadas por diferentes espécies de fungo micorrízico arbuscular durante as etapas de aclimatização e formação da muda, após período de doze meses. (média de cinco repetições)

\begin{tabular}{lcccccc}
\hline Fungo Micorrízico & \multicolumn{5}{c}{ Cultivar } \\
\cline { 2 - 7 } Arbuscular & Austral & Eidibel & Juréia & Luau & Netuno & Omega \\
\cline { 2 - 7 } & $1,09 \mathrm{~b}^{*}$ & $1,26 \mathrm{~b}$ & $1,16 \mathrm{~b}$ & $0,77 \mathrm{c}$ & $0,65 \mathrm{~b}$ & $0,54 \mathrm{~b}$ \\
Controle & $1,66 \mathrm{a}$ & $1,91 \mathrm{a}$ & $1,67 \mathrm{a}$ & $1,32 \mathrm{ab}$ & $1,16 \mathrm{a}$ & $0,90 \mathrm{a}$ \\
Glomus intraradices & $1,64 \mathrm{a}$ & $1,62 \mathrm{ab}$ & $1,55 \mathrm{ab}$ & $1,00 \mathrm{bc}$ & $0,75 \mathrm{~b}$ & $0,90 \mathrm{a}$ \\
Glomus etunicatum & $1,62 \mathrm{a}$ & $1,86 \mathrm{a}$ & $1,73 \mathrm{a}$ & $1,48 \mathrm{a}$ & $0,75 \mathrm{~b}$ & $1,00 \mathrm{a}$ \\
\hline Acaulospora sp. & & &
\end{tabular}

\footnotetext{
* Médias de cultivares seguidas por uma mesma letra não diferem entre si pelo teste de Tukey a $5 \%$. Coeficiente de variação experimental: $15 \%$.
} 
Tabela 2. Eficiência da simbiose (ES) em porcentagem estabelecida por fungos micorrízicos arbusculares em cultivares de Anthurium andraeanum durante as etapas de aclimatização e formação da muda, após doze meses.

\begin{tabular}{|c|c|c|c|c|c|c|}
\hline \multirow{2}{*}{$\begin{array}{l}\text { Fungo micorrízico } \\
\text { arbuscular }\end{array}$} & \multicolumn{6}{|c|}{ Cultivar } \\
\hline & Astral & Eidibel & Juréia & Luau & Netuno & Ômega \\
\hline Glomus intraradices & 34 & 34 & 31 & 42 & 44 & 40 \\
\hline Glomus etunicatum & 34 & 22 & 25 & 23 & 13 & 40 \\
\hline Acaulospora sp. & 33 & 32 & 33 & 48 & 13 & 46 \\
\hline
\end{tabular}

ES $(\%)=[($ matéria seca de plantas micorrizadas - matéria seca de plantas não micorrizadas) / matéria seca de plantas inoculadas $]$ x 100 .

Para a cultivar Netuno, entretanto, somente as plântulas colonizadas por G. intraradices diferiram significativamente da testemunha e dos demais FMAs, causando um incremento de $79 \%$ na matéria seca na parte aérea (Tabela 1), o que correspondeu a uma eficiência simbiótica de $44 \%$ (Tabela 2). Como essa cultivar é muito exigente em nutrientes (TомвоLAто, 2000), talvez a associação com $G$. intraradices tenha sido capaz de fornecer nutrientes adequadamente à planta, acarretando maior crescimento. Assim como na cultivar IAC Astral, na IAC Ômega também ocorreu maior ganho de matéria seca em todos os tratamentos com FMA, os quais diferiram significativamente da testemunha (Tabela 1). Os incrementos na produção de biomassa causados pelas simbioses foram de $67 \%$ para G. intraradices e G. etunicatum e de $85 \%$, para Acaulospora sp., enquanto a eficiência das simbioses foi cerca de $40 \%$ (Tabela 2). Apesar de ter apresentado o menor crescimento no período, foi a cultivar que mais se beneficiou da associação micorrízica.

As cultivares tiveram uma colonização radicular adequada (Tabela 3) e no geral, os fungos micorrízicos empregados não variaram entre si quanto à porcentagem de colonização. Durante a realização do experimento houve contaminação com FMA do substrato com as plantas do controle, com baixa colonização micorrízica. Tal colonização foi significativamente menor que a causada pelos FMAs introduzidos e, provavelmente, não causou benefício à planta, pois a produção de matéria seca do controle foi significativamente menor que das plantas dos tratamentos com fungos inoculados (Tabela 1).

Os resultados são um indicativo do papel que as micorrizas podem desempenhar no desenvolvimento dessa planta, especialmente no período de aclimatização da plântula micropropagada. Para a avaliação do papel das micorrizas na formação das mudas, o acúmulo de matéria seca foi bastante adequado, uma vez que plântulas colonizadas tiveram maior massa de matéria seca da parte aérea, em todas as cultivares utilizadas. Esses dados concordam com os obtidos por Silveira E Lima (1996) e por SoHn et al. (2003) para crisântemo e por GAUR e ADHOLEYA (2000) para petúnia, que também obtiveram aumento na matéria seca das mudas micorrizadas. Esse aumento poderia estar associado à maior absorção de nutrientes, posto que as raízes, em associação com o FMA, exploraram maior volume de substrato que, entretanto, não recebeu nenhuma adubação complementar, mesmo alguns nutrientes estando em baixa concentração, como o fósforo. Os resultados obtidos foram de encontro ao objetivo visado durante a fase de produção de mudas, ou seja, o crescimento rápido e vigoroso das plântulas.

Tabela 3. Colonização micorrízica em porcentagem de cultivares de Anthurium andraeanum por diferentes fungos micorízicos arbusculares, após doze meses, durante as etapas de aclimatização e formação da muda

\begin{tabular}{lcccccc}
\hline Fungo micorrízico & \multicolumn{5}{c}{ Cultivar } \\
\cline { 2 - 7 } arbuscular & Austral & Eidibel & Juréia & Luau & Netuno & Ômega \\
\cline { 2 - 7 } & & & & & & \\
& & & & & & \\
Controle & $8,0 \mathrm{~b}$ & $4,17 \mathrm{~b}$ & $8,0 \mathrm{~b}$ & $7,6 \mathrm{c}$ & $4,37 \mathrm{~b}$ & $6,0 \mathrm{~b}$ \\
Glomus intraradices & $40,1 \mathrm{a}$ & $40,2 \mathrm{a}$ & $43,5 \mathrm{a}$ & $34,8 \mathrm{~b}$ & $31,6 \mathrm{a}$ & $41,7 \mathrm{a}$ \\
Glomus etunicatum & $46,6 \mathrm{a}$ & $34,4 \mathrm{a}$ & $48,2 \mathrm{a}$ & $48,9 \mathrm{a}$ & $31,0 \mathrm{a}$ & $50,9 \mathrm{a}$ \\
Acaulospora sp. & $38,5 \mathrm{a}$ & $42,1 \mathrm{a}$ & $39,2 \mathrm{a}$ & $44,1 \mathrm{ab}$ & $32,2 \mathrm{a}$ & $45,6 \mathrm{a}$ \\
\hline
\end{tabular}

* Médias de cultivares seguidas por uma mesma letra não diferem entre si pelo teste de Tukey a 5\%. 
No grupo de cultivares empregadas, as respostas varietais foram bastante distintas, sendo isso uma possível indicação de diferentes afinidades entre cultivares de antúrio e FMAs. LINDERMAN e DAVIS (2004), para diferentes genótipos de Tagetes spp., também observaram variação significativa na resposta das diferentes cultivares em relação às espécies de fungos micorrízicos. É possível afirmar que a introdução de fungos micorrízicos ao substrato de cultivo, nos vasos, durante as etapas de aclimatização e formação da muda, aumentou a quantidade de matéria seca acumulada na parte aérea das plântulas de todas as cultivares. G. intraradices foi a única espécie de FMA eficiente em todas as cultivares empregadas. Parke e Kaeprler (2000) alertam que pelas técnicas de melhoramento de plantas, pode-se estar selecionando plantas com menor capacidade genética para responder positivamente à associação micorrízica, pelo menos em termos de produção de biomassa, o que seria indesejável para $\mathrm{o}$ antúrio que foi responsivo à micorrização.

\section{Conclusões}

1. Houve resposta das cultivares de Anthurium andraeanum à micorrização, em termos de produção de matéria seca.

2. A eficiência simbiótica variou com a cultivar e o fungo micorrízico associado.

\section{Agradecimentos}

Os autores agradecem ao Dr. Luis Alberto Saes do Polo Regional do Vale do Ribeira / APTA e ao Eng. ${ }^{\circ}$ Agr. ${ }^{\circ}$ Eduardo Jun Fujitani, gerente do Laboratório de Micropropagação da AFLOVAL (Associação dos Floricultores do Vale do Ribeira), pela doação das plântulas de antúrio. Também, agradecem à técnica de laboratório Rosana Gonçalves Giertz, do Centro de Solo e Recursos Ambientais, IAC, pela colaboração na instalação e no desenvolvimento do experimento.

\section{Referências Bibliográfica}

GAUR, A.; ADHOLEYA, A. Growth and flowering in Petunia hybrida, Callistephus chinensis and Impatiens balsamina inoculated with mixed AM inocula or chemical fertilizers in a soil of low P fertility. Scientia Horticulturae, Amsterdan, v.94, p. 151-162, 2000.
GAUR, A.; ADHOLEYA, A. Diverse response of five ornamental plant species to mixed indigenous and single isolate arbuscular-mycorrhizal inocula in marginal soil amended with organic matter. Journal of Plant Nutrition, New York, v.28, n.4, p. 707-723, 2005.

GIOVANETTI, M.; MOSSE, B. Na evaluation of techniques for measuring vesicular arbuscular mycorrhizal infection in roots. New Phytologist, Cambridge, v. 84, p. 489-500, 1980.

GRATTAPAGLIA, D.; MACHADO, M.A. Micropropagação. In: TORRES, A.C.; CALDAS, L.S. (Eds.). Técnicas e aplicações da cultura de tecidos de plantas. Brasília: ABCTP/EMBRAPA CNPH, 1990. p.99-169,

JOHNSON, C.R.; GRAHAM, J.H.; LEONARD, R.T.; MENGE, J.A. Effect of flower bud development in chrysanthemun on vesicular-arbuscular mycorrhiza formation. The New Phytologist, London, v. 85, p. 671-675, 1982.

KAYE, J.W.; PFLEGER, F.L.; STEWART, E.L. Interaction of Glomus fasciculatum and Pytium ultimun on greenhouse-grown poinsettia. Canadian Journal of Botany, Ottawa, v.62, p. 15751579, 1984.

KLINGEMAN, W.E.; van IERSEL, M.W.; KANG, J.G.; AUGÉ, R.M.; MOORE, J.L.; FLANAGAN, P.C. Whole-plant gas exchange measurements of mycorrhizal 'Iceberg'roses exposed to cyclic drought. Crop Protection, Guildford, v.24, p.309-317, 2005.

KOZAI, T.; OKI, H.; FUJIWARA, K. Effects of $\mathrm{CO}_{2}$ enrichment and sucrose concentration under high photosynthetic photon fluxes on growth of tissue-cultured Cymbidium plantlets during the preparation stage. Plant micropropagation in horticultural industries. Proceedings of the ${ }^{\circ}$ Symposium Floriezel, ARLON, V.87, p. 135-141, 1987.

KOZAI, T. Photoautotrophic micropropagation. In vitro Cellular Developmental Biology, New York, v.27, p. 4751, 1991.

LINDERMAN, R.G.; DAVIS, E.A.. Varied response of marigold (Tagetes spp.) genotypes to inoculation with different arbuscular mycorrhizal fungi. Scientia Horticulturae, Amsterdam, v.99, p. 67-78, 2004.

MATTHES, L.A.F.; CASTRO, C.E.F. O cultivo de antúrio: produção comercial. Campinas: Instituto Agronômico (IAC), 1989. 22p. (Boletim Técnico n. 126)

PARKE, J.L.; KAEPPLER, S.A. Effects of genetic differences among crop species and cultivars upon the arbuscular mycorrhizal symbiosis. In: KAPULNIK, Y.; DOUDS, D.D. (Eds.). Arbuscular mycorrhizas: Physiology and function, Dordrecht: Kluwer Academic Publishers, 2000. p. 131-146.

PHILLIPS, J.M.; HAYMAN, D.S. Improved procedures for clearing roots and staining parasitic and vesicular-arbuscular mycorrhizal fungi for rapid assessment of infection. Transaction British Mycological Society, Londres, v.55, p. 158$161,1970$. 
SILVA,L.R.C.; ARELLO, E.F.; SILVA, M.A. Efeito de fungos micorrízicos vesículo-arbusculares sobre o desenvolvimento de mudas micropropagadas de Gerbera jamensonii. In: REUNIÃO BRASILEIRA SOBRE MICORRIZAS, 4., Mendes, 1991. Resumos... Mendes: EMBRAPA-CNPBS, 1991. p. 151.

SILVEIRA, A.P.D. Micorrizas. In: CARDOSO, E.J.B.N.; TSAI, S.M.; NEVES, M.C. (Eds.). Microbiologia do solo. Campinas: Sociedade Brasileira de Ciência do Solo, 1992. p. 257-282.

SILVEIRA, A.P.D.; LIMA, A.M.L.P. Influência de diferentes espécies de fungo micorrízico arbuscular no desenvolvimento do crisântemo. Bragantia, Campinas, v.55, p. 177-184, 1996.

SOHN, B.K.; KIM, K.Y.; CHUNG, S.J.; KIM, W.S.; PARK, S.M.; KANG, J.G.; RIM, Y.S.; CHO, J.S.; KIM, T.H.; LEE, J.H. Effect of the different timing of AMF inoculation on plant growth and flower quality of chrysanthemum. Scientia Horticulturae, Amsterdam, v.98, p. 173-183, 2003.
SWEATT, M.R.; DAVIES JR, F.T. Mycorrhizae, water relations, growth, and nutrient uptake of geranium grown under moderately high phosphorus regimes. Journal American Society Horticulture Science, New York, v. 109, n. 2; p. 210-213, 1984.

TOMBOLATO, A.F.C. Seleções IAC de antúrios. O Agronômico, Campinas, v.52, n.1, p. 26-27, 2000.

TOMBOLATO, A.F.C.;FURLANI,P.R.;CASTRO, C.E.F.;MATHES, L.A.F.; TAGLIACOZZO, G.M.D.; SAES, L.A.; RIVAS, E.B.; COUTINHO, L.N.; BERGAMANN, E.C.; LEME, J.M. Antúrio. In: A.F.C. TOMBOLATO (Ed.). Cultivo Comercial de Plantas Ornamentais. Campinas: Instituto Agronômico, 2004. p. 61-94.

TOMBOLATO, A.F.C.; SAES, L.A; MATHES, L.A.F.;SAKAI, M.; TAGLIACOZZO, G.M.D.; CASTRO, C.E.F. de; VEIGA, R.F.A.; BARBOSA, W. New varieties of Anthurium andreanum from Brazil. Acta Horticulture, Wageningen, 683, p. 423-430, 2005.

VARMA, A.; SCHÜEPP,H. Positive influence of arbuscular mycorrhizal fungus on in vitro raised hortensia plantlets. Angew Botany, v.68, p.108-115, 1994. 